\title{
Efficacy of a Patient's Own Blood as Colonic Localization Agent
}

\author{
Dae Youn Won, Won-Kyung Kang \\ Department of Surgery, Seoul St. Mary's Hospital, The Catholic University of Korea College of Medicine, Seoul, Korea
}

\section{See Article on Page 115-117}

Preoperative tumor localization is an important issue in laparoscopic surgery due to poor tactile sensation [1], and small lesions are sometimes removed by colonoscopy even before surgery. Among various methods in localization, colonoscopic tattooing is commonly performed [2]. The efficacy of tattooing has been reported, and one study showed that the tattooed group had a $100 \%$ localization rate, lower operative time and lower blood loss [3]. Indocyanine green and India ink have been used over other dyes such as methylene blue because of their good staining effect and persistency [4]. Especially, India ink stain persists for more than 10 years and serves as a permanent marker. Although commonly used, India ink tattooing does have its rare complications, such as mucosal ulceration, inflammation, an inflammatory pseudo-tumor, and even peritonitis. While other recent studies have focused on the localization efficacy and the accuracy of colonoscopic tattooing [5], this paper reminds us of the potential complications with the use of India ink, a foreign material to the body [6]. To overcome the clinical problems caused by reactions to such foreign material is to use the patient's own blood and promote patient safety. In this study, efforts to find an economic and accessible way to reduce the complications from colonoscopic tattooing are described; here the authors conclude that using patient's own blood is feasible for preoperative localization [7]. Apparent limitations of this study are that it is retrospective and that it is based on a small patient population. A larger-scale, well-designed, prospec-

Correspondence to: Won-Kyung Kang, M.D.

Department of Sugery, Seoul St. Mary's Hospital, The Catholic University of Korea College of Medicine, 222 Banpo-daero, Seocho-gu, Seoul 137-701, Korea

Tel: +82-2-2258-6104, Fax: +82-2-595-2822

E-mail: wonkkang@catholic.ac.kr

(c) 2014 The Korean Society of Coloproctology

This is an open-access article distributed under the terms of the Creative Commons Attribution NonCommercial License (http://creativecommons.org/licenses/by-nc/3.0) which permits unrestricted noncommercial use, distribution, and reproduction in any medium, provided the original work is properly cited. tive study is necessary if the use of a patient's own blood as a tattooing method is to become widely accepted as the new standard technique. Furthermore, comparative studies with other new injection materials, such as a pure carbon suspension [8] or iodineactivated indocyanine green [9], may be necessary. This paper proposes a safe and simple method of using a patient's own blood to localize early colorectal cancer or a malignant polyp during the preoperative period.

\section{REFERENCES}

1. Hancock JH, Talbot RW. Accuracy of colonoscopy in localisation of colorectal cancer. Int J Colorectal Dis 1995;10:140-1.

2. Park JW, Sohn DK, Hong CW, Han KS, Choi DH, Chang HJ, et al. The usefulness of preoperative colonoscopic tattooing using a saline test injection method with prepackaged sterile India ink for localization in laparoscopic colorectal surgery. Surg Endosc 2008; 22:501-5.

3. Arteaga-Gonzalez I, Martin-Malagon A, Fernandez EM, ArranzDuran J, Parra-Blanco A, Nicolas-Perez D, et al. The use of preoperative endoscopic tattooing in laparoscopic colorectal cancer surgery for endoscopically advanced tumors: a prospective comparative clinical study. World J Surg 2006;30:605-11.

4. Price N, Gottfried MR, Clary E, Lawson DC, Baillie J, Mergener K, et al. Safety and efficacy of India ink and indocyanine green as colonic tattooing agents. Gastrointest Endosc 2000;51(4 Pt 1): 438-42.

5. Solon JG, Al-Azawi D, Hill A, Deasy J, McNamara DA. Colonoscopy and computerized tomography scan are not sufficient to localize right-sided colonic lesions accurately. Colorectal Dis 2010; 12(10 Online):e267-72.

6. Nizam R, Siddiqi N, Landas SK, Kaplan DS, Holtzapple PG. Colonic tattooing with India ink: benefits, risks, and alternatives. Am J Gastroenterol 1996;91:1804-8.

7. Lee SH, Kim DY, Oh SY, Lee KJ, Suh KW. Preoperative localization of early colorectal cancer or a malignant polyp by using the patient's own blood. Ann Coloproctol 2014;30:115-7.

8. Askin MP, Waye JD, Fiedler L, Harpaz N. Tattoo of colonic neo- 


\section{Coloproctology}

\section{Efficacy of a Patient's Own Blood as Colonic Localization Agent}

Dae Youn Won and Won-Kyung Kang

plasms in 113 patients with a new sterile carbon compound. Gastrointest Endosc 2002;56:339-42.

9. Watanabe M, Tsunoda A, Narita K, Kusano M, Miwa M. Colonic tattooing using fluorescence imaging with light-emitting diodeactivated indocyanine green: a feasibility study. Surg Today 2009; 39:214-8. 